\title{
Editorial
}

\section{The next five years}

This issue sees the completion of the first five years of the fournal's existence. During this initial period the primary task of the editors and the editorial board has been to establish a consistent standard in main articles and regular features, upon which our steadily increasing readership may rely. This has not always been an easy task and we would be the first to admit that there is much room for improvement in the next five years. Of course the success of the fournal is attested by the fact that it has now become an authoritative source of reference for medical textbooks and for other scholarly journals. But it is more salutary to look at the problem of maintaining both depth and range of coverage in a publication of this kind than to rest content on our achievements so far. Part of the difficulty lies in the tendency for some aspects of medical ethics to be given a disproportionate amount of attention, notably (at the present time) the moral issues associated with death and the dying patient. (A timely warning given to the editor recently was that the fournal might have to be renamed 'The Journal of Medical Thanatology'!) A consequence of this imbalance in the interests of those actively writing in the field of medical ethics is that a number of good papers on euthanasia and related topics simply cannot be published, whilst papers on neglected topic areas (such as dilemmas of health care in the community, ethical dilemmas in nursing, moral problems in care of the handicapped) are hard to come by, even through direct editorial commissioning. Nevertheless we have tried to maintain a wide range of subjects in each volume, if not always in each issue. Readers will have the opportunity of reviewing this range in the June issue each year, when a cumulative list of our main articles arranged in topic areas is published. A principal task of the fournal in the next five years must be to stimulate research and writing in neglected areas of medical ethics, where the moral issues are no less important than those currently in vogue in public discussions.

\section{International contacts}

We welcome in this issue a new regular feature, Letter from Australia by Dr Anthony Moore of the Department of Surgery, University of Melbourne. or Dr Moore has already published two articles in the fournal, one describing his use of literary works in $\overrightarrow{\mathscr{G}}$ medical education ${ }^{1}$ and the other a short item $\dot{0}$ for our occasional feature Point of View, entitled, 음 'More blessed to receive ?'2 (The latter article was re-published in an Australian national newspaper at $\mathbb{\Phi}$ a time of controversy about doctors' salaries.) We $₫$ are publishing the first of Anthony Moore's Australian letters in the same issue as Bernard Towers' now well established Report from Americ $8 \vec{\theta}$ but in the future these two international reports wi 0 appear alternately. The editors will welcom reports on topical issues in medical ethics from other parts of the world, either as regular features or as occasional additional reports.

\section{'What's in a name?'}

A major change in regular features will take place in the first issue of the next volume. Our series Analysis, which has attempted to provide a concise introduction to ethical concepts in layman's language, ends in this issue. (Readers should note that Case Conference, although omitted on this occasion for reasons of space, will continue in the new volume.) In place of Analysis we are introducing a new series entitled Words. Articles in this new series will range more widely than those of its predecessor, since it will be concerned with the ambiguities of language in a number of fields, and not merely with the technical terms of moral philosophy. Thus we regard the new series as a $\stackrel{\mathbb{D}}{\sim}$ natural extension to the groundwork already laid by 0 Analysis. The series will be launched by Professor Robin Downie (who was the author of the first Analysis article in Volume $\mathrm{I}$, Number I) with a $\stackrel{\mathbb{Q}}{\mathrm{Q}}$ discussion of those much used and abused words $\bar{Q}$ 
'ethics' and 'morals'. We hope that this new series will help promote one of the main aims of the fournal - the improvement of communications among the many disciplines engaged in the study of medical ethics. No doubt roses smell sweet by any name, but it is helpful in some contexts to know which flora are being discussed. That, at times, pedantic task we gladly undertake, though not we $\stackrel{8}{\stackrel{8}{\alpha}}$ hope with too much solemnity.

\section{References}

${ }^{1}$ Moore, A. (1977). Medical humanities: an aid to ethical discussions. Fournal of medical ethics, 3, 26-32.

${ }^{2}$ Moore, A. (1979). More blessed to receive ? fournal of 0 medical ethics, 5, 33-34. 